\title{
Encefalitis por anticuerpos antirreceptor de n-metil-d-aspartato. Reporte de caso.
}

\author{
Encephalitis associated with
}

Anti-n-methyl-d-aspartate receptor antibodies. Case report.

\author{
Julieta Palm, Eugenia Labaronnie, Gianna Bassi, Emiliano Lingua, Juan C. Pendino, Roberto \\ Parodi, Sergio Lupo.
}

Universidad Nacional de Rosario. Facultad de Ciencias Médicas. Cátedra de Clínica Médica. Rosario; Argentina. Hospital Provincial del Centenario. Servicio de Clínica Médica. Rosario; Argentina.

Autor por correspondencia: Roberto Parodi — drrobertoparodi@gmail.com

Conflicto de intereses: no presenta.

\begin{abstract}
Resumen
La encefalitis por anticuerpos contra el receptor N-metil-D— aspartato (NMDA) es una patología neurológica autoinmune reconocida recientemente en el año 2007 que afecta principalmente a adultos jóvenes, predominantemente mujeres y niños. Un gran porcentaje está asociado a procesos tumorales. Clínicamente los pacientes desarrollan de manera rápida y secuencial síntomas neuropsiquiátricos, crisis convulsivas que progresan hacia un rápido deterioro del nivel de consciencia, mutismo, catatonía y movimientos anormales. Es una patología potencialmente reversible y el grado de secuelas va a depender de la rapidez en el inicio del tratamiento.

Se presenta el caso de un paciente joven que debutó con conductas autoagresivas y alucinaciones. Cursó posteriormente con trastornos de memoria y lenguaje, alteraciones conductuales y convulsiones y presentó anticuerpos contra receptores NMDA en el líquido cefalorraquídeo (LCR). Realizó tratamiento con inmunoglobulinas y corticoides con evolución favorable logrando control y no progreso de la enfermedad.
\end{abstract}

Palabras clave: Anticuerpos. Antirreceptor $\mathbf{n}-$ metil-d-aspartato. Encefalitis autounmune. Receptores de $n-$ metil-d-aspartato. Síntomas neuropsiquiátricos.

\begin{abstract}
Encephalitis associated with anti-N-methyl-D—aspartate (NMDA) receptor antibodies is an autoimmune neurological condition recently recognized in 2007. It mainly affects young adults-especially women-and children. A large percentage is associated with tumour processes. Patients develop neuropsychiatric symptoms in a rapid and sequential way and they have convulsive crises that rapidly result in decreasing levels of consciousness, mutism, catatonia and abnormal movements. It is a potentially reversible condition and the seriousness of its effects will depend on how soon the patient receives treatment.
\end{abstract}


This paper describes the case of a young patient who initially displayed self-injurious behaviour and had hallucinations. Later, he had memory and language impairment, behavioral disorders, seizures and anti-NMDA receptor antibodies in the cerebrospinal fluid. He had a favourable response to immunoglobulins and corticosteroids with control and stabilization of the disease.

Keywords: Antibodies. Anti-n-methyl-d-aspartate receptor. Autoinmmune encephalitis. $\mathrm{N}-$ methyl-d-aspartate receptors. Neuropsychiatric symptoms.

\section{Introducción}

La encefalitis por anticuerpos contra el receptor N-metil-D- aspartato (NMDA) es una patología neurológica autoinmune de instauración subaguda (en más de 3 semanas) que afecta principalmente a adultos jóvenes pero también puede afectar a adolescentes y niños, siendo el $40 \%$ de los casos menores de 18 años; predominantemente afecta a mujeres hasta en un 80\% del total de los casos. Es un síndrome autoinmune que puede estar o no asociado a un tumor. Su incidencia exacta no se conoce pero en base al incremento en el reporte de casos, parece ser más frecuente que cualquier otra encefalitis paraneoplásica (1). Clínicamente los pacientes desarrollan de manera rápida y secuencial síntomas neuropsiquiátricos, crisis convulsivas que progresan hacia un rápido deterioro del nivel de consciencia, mutismo, catatonía y movimientos anormales. Es una patología potencialmente reversible y el grado de secuelas va a depender de la rapidez en el inicio del tratamiento. El diagnóstico se basa en la sospecha clínica y la demostración de anticuerpos NMDA en el LCR con una sensibilidad del 100\% disminuyendo la misma cuando se dosan en plasma (85\%) (2). Tras la confirmación se debe conducir a la búsqueda de un tumor. La Resonancia Nuclear Magnética (RNM) cerebral puede mostrar hiperintensidades en T2 o FLAIR en las áreas hipocámpales, cerebelo, corteza cerebral, fronto-basal, las regiones insulares, los ganglios basales y el tronco cerebral en un 50\% de los pacientes. Los hallazgos suelen ser leves o transitorios y pueden ir acompañados de sutil mejoría en las zonas afectadas una vez instaurado el tratamiento. La biopsia cerebral no es el Gold estándar para realizar el diagnóstico (3).

Entre los diagnósticos diferenciales de la NMDA, se han planteado históricamente con diferentes enfermedades toxicas, metabólicas, infecciosas, autoinmunitarias, entre otros.

A la hora de realizar tratamiento si es encontrado un tumor, el tratamiento inicial consiste en su extirpación, ya que esto acelera la mejoría clínica y disminuye las recaídas. Por tratarse de una patología inmune mediada, el tratamiento se realiza con terapias inmunomoduladoras. Se considera la utilización de corticoides, a la plasmaféresis y a las inmunoglobulinas como primera línea terapéutica y al rituximab y/o ciclofosfamida como segunda línea (4). En aquellos casos refractarios el uso de bortezomid, alemtuzumab, entre otros podrían ser de utilidad.

El cuadro clínico, a pesar de la situación de gravedad y el importante deterioro neurológico potencialmente reversible, muestra una mejoría de los síntomas en cronología inversa a las fases de presentación. Los síntomas responden tanto al tratamiento del tumor, en caso de haberlo, como a la inmunoterapia. Los factores predictores de buena evolución son la gravedad de los síntomas, el no cursar internación en cuidados intensivos y el inicio de un tratamiento precoz. La respuesta al tratamiento inmunosupresor puede ser lenta, se estiman recaídas entre un $12-25 \%$ entre un mes y 8 años tras la recuperación, y una mortalidad del 7\%.

\section{Caso clínico}

Los datos en relación al caso clínico fueron obtenidos de la historia clínica del paciente quien de forma voluntaria nos dio su consentimiento para que de manera anónima los mismos puedan ser utilizados en presentaciones en congresos, reuniones científicas o publicaciones de reporte en una revista científica. Se trata de varón de 19 años, con antecedentes de asma en la infancia y tabaquista ocasional, quien es llevado a la consulta por familiares por cuadro de 2 meses de evolución caracterizado por conductas autoagresivas y alucinaciones auditivas luego de una situación de estrés emocional, lo que motivó a múltiples consultas por lo que se indicó tratamiento con benzodiacepinas y neurolépticos (haloperidol, lorazepam). Presentó progresivamente apatía, mutismo, rigidez y convulsiones tónico clónicas por lo que inicialmente cursó internación en unidad de terapia intensiva. Al examen físico se encontraba afebril, presentaba facie inexpresiva, discinesias oro-linguo-faciales, movimientos oculógiratorios, espasticidad de los cuatros miembros e hiperreflexia, sin signos meníngeos. A nivel analítico se constató valor de leucocitos y reactantes de fase aguda dentro de rango normal, evidenciándose elevación de enzimas musculares (tabla 1). 
Tabla 1: Laboratorio solicitados al ingreso del paciente.

\begin{tabular}{|l|c|l|c|}
\hline Hemoglobina (g/dL) & 15.2 & Calcio (mg/dl) & 8.7 \\
\hline Hematocrito (\%) & 43.4 & Fósforo (mg/dl) & 2.2 \\
\hline Blancos (cel/mm) & 8300 & Magnesio (mg/dl) & 1.9 \\
\hline Plaquetas (/mm) & 251000 & Bilirrubina total (mg/dl) & 0.92 \\
\hline VES (mm/1 ${ }^{\circ}$ hora) & 8.0 & TGO (UI/l) & 151 \\
\hline PCR (mg/L) & 3.5 & TGP (UI/l) & 34 \\
\hline Glicemia (mg/dl) & 152 & FAL (UI/l) & 106 \\
\hline Urea (mg/dl) & 33 & GGT (UI/l) & 15 \\
\hline Creatinina (mg/dl) & 1.08 & Amilasa (UI/l) & 40 \\
\hline Sodio (mEq/l) & 140 & Albúmina (g/dl) & 4.9 \\
\hline Potasio (mEq/I) & 3.93 & CPK (UI/l) & 9255 \\
\hline Cloro (mEq/l) & 97 & LDH (UI/l) & 698 \\
\hline
\end{tabular}

Se realizó una resonancia magnética de cráneo y posteriormente una punción lumbar para análisis del LCR en los cuales no se evidenciaron hallazgos de jerarquía (imagen 1 y tabla 2).

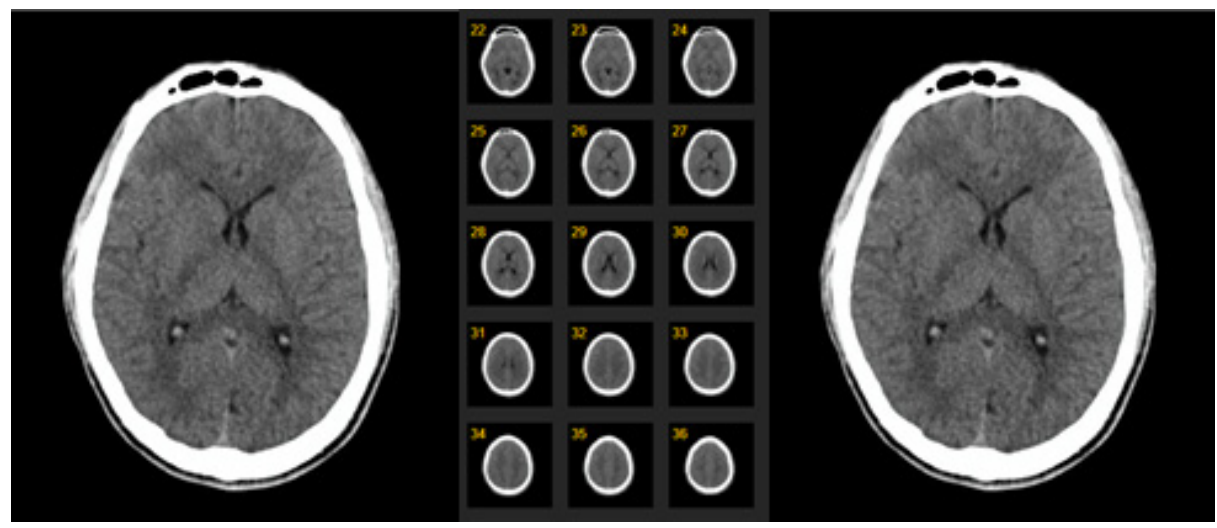

Imagen 1: resonancia magnética de cráneo

Tabla 2: Citofisicoquímico de LCR

\begin{tabular}{|l|c|l|l|}
\hline Glucosa $(\mathrm{g} / \mathrm{l})$ & 0.75 & Pandy & Negativo \\
\hline Proteínas $(\mathrm{g} / \mathrm{l})$ & 0.27 & Tinta china & Negativo \\
\hline Elementos & 2 & VDRL & Negativo \\
\hline
\end{tabular}

Como parte del estudio por los episodios de convulsiones se realizó electroencefalograma en el que se evidenció trazado dentro de parámetros normales. Evolucionó desfavorablemente persistiendo con cuadro de excitación psicomotriz y convulsiones a pesar del tratamiento anticomicial, con requerimiento de sedación y vinculación a asistencia respiratoria mecánica. El diagnóstico presuntivo inicial fue el de un síndrome neuroléptico maligno al presentar elevación de enzimas musculares, rigidez muscular, antecedentes de indicación de neurolépticos, taquicardia y deterioro del sensorio, pero no presentó mejoría tras la suspensión de dichos fármacos por lo que se realizaron nuevos exámenes complementario. Se realizó una segunda neuroimagen la cual evidenció engrosamiento paquimeníngeo difuso con refuerzo tras la administración de contraste (imagen 2) realizándose posteriormente una segunda punción lumbar con evidencia de pleocitosis a predominio de polimorfonucleares (tabla 3). 


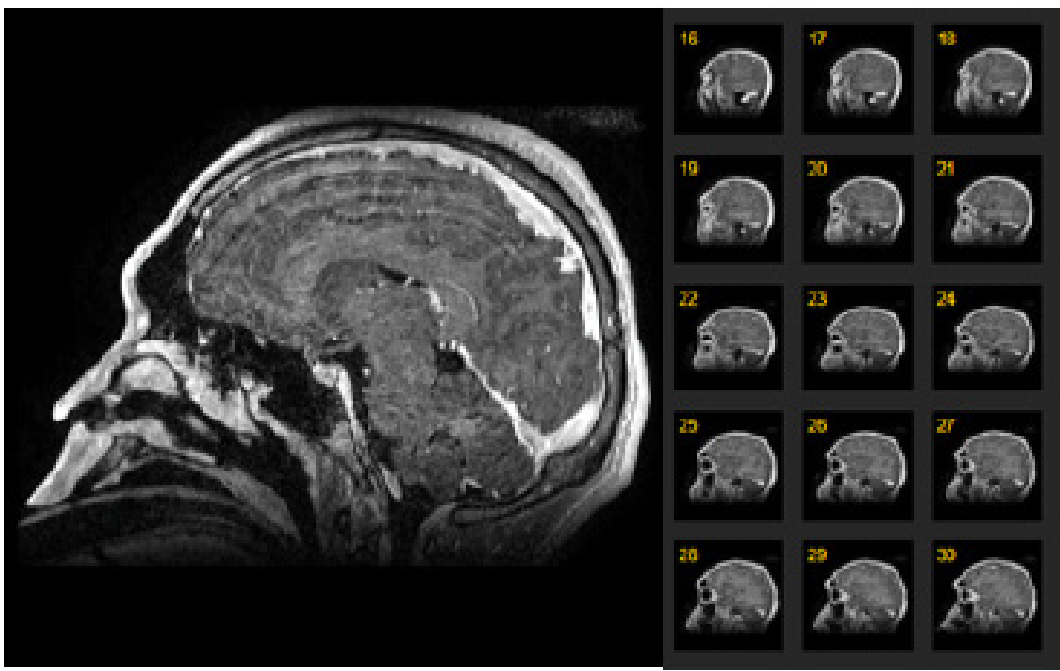

Imagen 2: resonancia magnética de cráneo con contraste.

Tabla 3: Citofisicoquímico de líquido cefalorraquídeo de la segunda punción lumbar.

\begin{tabular}{|l|c|l|c|}
\hline Glucosa $(\mathrm{g} / \mathrm{l})$ & 1.06 & Pandy & Positivo \\
\hline Proteínas $(\mathrm{g} / \mathrm{l})$ & 0.7 & Tinta china & Negativo \\
\hline Elementos & 2 & VDRL & Negativo \\
\hline
\end{tabular}

Se realizaron serologías virales (virus herpes simple 1 y 2 , virus varicela zoster, enterovirus) y cultivo microbiológico (gérmenes comunes y bacilo acido alcohol resistente) en LCR los cuales fueron negativos. Por no poder descartar etiología infecciosa se instauró antibioticoterapia empírica sin evidenciar mejoría y ante la falta de respuesta a los tratamientos instaurados se solicitó anticuerpo anti-NMDA en LCR resultando positivo, llegando al diagnóstico de encefalitis autoinmune por anticuerpos anti-NMDA. Realizó tratamiento con corticoterapia e inmunoglobulina G evidenciándose respuesta favorable a las 2 semanas del mismo.

Además se descartó la presencia de una neoplasia subyacente mediante screening endocrinológico (perfil tiroideo y anticuerpos anti-tiroideos), por imágenes (ecografía testicular y abdominal y radiografía de tórax) y con marcadores tumorales (alfafetoproteína, gonadotrofina coriónica humana y carcinoma embrionario) como así causas de encefalitis tóxicas ya que al ingreso el paciente había presentado negatividad de los mismos en orina (cocaína, marihuana, éxtasis, barbitúricos, opioides, tricíclicos y fenciclidina).

\section{Discusión}

La encefalitis autoinmune es una patología infrecuente y descripta recientemente. El diagnóstico suele retrasarse al confundirse con encefalitis virales, procesos psiquiátricos primarios, ingestas de drogas y síndrome neuroléptico maligno, coincidiendo con los planteos diagnósticos diferenciales pensados inicialmente en este caso. La etiología autoinmune debe considerarse en los cuadros con alteraciones de la conducta, cognición y compromiso de la conciencia de instauración subaguda, una vez descartadas las causas infecciosas, metabólicas y vasculares.

En los últimos 10 años pasó de ser un síndrome paraneoplásico raro a constituirse como la primera causa de encefalitis no-virales. Fue descripta por primera vez por Dalmau y co. en una serie de casos que incluyó a 4 mujeres con encefalitis mediada por anticuerpos anti receptor NMDA, las cuales todas presentaban teratoma de ovario $(5,6)$.

El primer trabajo estadísticamente significativo fue publicado en LANCET Neurology en el 2013, se trata de un estudio de cohorte observacional, prospectivo, en el que se enrolaron en total 577 pacientes entre el año 2001 y 2013, se observó que la edad promedio de presentación son los 21 años, que aparece predominantemente en mujeres, y asociado a neoplasias en el 50\% de los casos, de los cuales 95\% son teratomas ováricos $(7,8)$. Ante la sospecha de que se trate de un síndrome paraneoplásico se deben 
realizar los estudios pertinentes para descartar la presencia de un tumor asociado para poder iniciar el tratamiento oportuno debiendo tener presente que el rastreo de una neoplasia oculta debe hacerse durante cuatro años consecutivos (en mujeres con RMI de abdomen y pelvis cada 6 meses).

Generó evidencia en relación a que se trata de una patología potencialmente reversible, siempre y cuando el tratamiento sea precoz y adecuado, los pacientes que no recibieron inmunoterapia tuvieron un desenlace letal o bien secuelas graves. Sin embargo 74\% de los pacientes presentaron buena respuesta a inmunoterapia de lera, o lera y 2 da línea. El tratamiento de 2da línea se relacionó con menor tasa de recaídas.

El diagnóstico del paciente mencionado se realizó al descartar las encefalitis más frecuentes en nuestro medio. Se sospechó de encefalitis de etiología autoinmune en primer lugar por el deterioro clínico progresivo y rápido que presentó el paciente a pesar del tratamiento médico inicialmente instaurado y, en segundo lugar, al encontrar positivos los anticuerpos NMDA en el LCR. No se realizó determinación de anticuerpos NMDA en suero ya que por lo reportado en la literatura los mismos poseen menor sensibilidad.

Se debe tener en cuenta que existe posibilidad de que encefalopatías virales (la producida por virus herpes simple) pueden semanas posteriores producir encefalitis por anticuerpos anti NMDA.

Fuente de financiamiento: no presenta.

\section{Referencias Bibliográficas}

1. Erazo R, González J, Quintanilla C, et al. Encefalitis subaguda por anticuerpos anti receptor de N-metil-D-aspartato. Rev. chil. pediatr. 2016. 87 (6): 487-493.

2. González Valcárcel J, Rosenfeld M, Dalmau, J. Diagnóstico diferencial en la encefalitis por anticuerpos contra el receptor NMDA. Neurologia. 2010. 25 (7): 409-413

3. Suárez D, Rojas JP, Castillo, et al. Encefalitis por Anticuerpos contra el Receptor N-metil D-aspartato (NMDAR) en Pediatría. Reporte de caso y revisión de la literatura. Acta Neurol Colomb. 2014; 30(3):193-199.

4. Collao Parra JP, Romero Urra C, Delgado Derio C. Encefalitis autoinmunes: criterios diagnósticos y pautas terapéuticas. Rev Med Chile 2018; 146: $351-361$.

5. Dalmau J, Gleichman AJ, Hughes EG, et al. Anti-NMDA-receptor encephalitis: case series and analysis of the effects of antibodies. Lancet Neurol. 2008;7(12):1091-1098

6. Dalmau J, Lancaster E, Martinez-Hernandez E, Rosenfeld MR, Balice-Gordon R. Clinical experience and laboratory investigations in patients with anti-NMDAR encephalitis. Lancet Neurol. 2011;10(1):63-74.

7. Gresa-Arribas N, Titulaer MJ, Torrents A, et al. Antibody titres at diagnosis and during follow-up of anti-NMDA receptor encephalitis: a retrospective study [published correction appears in Lancet Neurol. 2014 Feb;13(2):135]. Lancet Neurol. 2014;13(2):167-177.

8. Titulaer MJ, McCracken L, Gabilondo I, et al. Treatment and prognostic factors for long-term outcome in patients with anti-NMDA receptor encephalitis: an observational cohort study. Lancet Neurol. 2013;12(2):157-165. 